\title{
Analysis of Asymmetric Quantity Commitment in Decentralized Supply Chains
}

\author{
Zhaoqiong Qin, Savannah State University, USA \\ Wen-Chyuan Chiang, University of Tulsa, USA \\ Robert Russell, University of Tulsa, USA
}

\begin{abstract}
Quantity commitment chosen by firms in competition has been demonstrated by previous studies to mitigate price competition. This study demonstrates that asymmetric quantity commitment can always arise when one firm (e-tailer) shortens lead times or adopts just-in-time systems to circumvent quantity commitment while another firm (retailer) does not. To study the asymmetric quantity commitment in decentralization, a multi-stage game is analyzed, and backward induction is adopted. The authors find that the retailer always adopts the quantity commitment in the decentralization to achieve a higher profit.
\end{abstract}

\section{KEYWORDS}

Asymmetric Quantity Commitment, Backward Induction, Decentralization, Game Theory, Multi-Stage

\section{INTRODUCTION}

Quantity commitment has attracted much attention in the academic community and in industry practices to mitigate price competition. The seminal work includes Nasser and Turcic (2016), Kreps and Scheinkman (1983) and Singh and Vives (1984). For instance, Singh and Vives (1984) assume that the firm that chooses quantity commitment will not set a price at a subsequent stage and the specific price is followed by default to clear the entire committed quantity. However, none of the studies considers the scenario where heterogeneous consumers on the market and product value differentiation from different channels lead to price differentiation simultaneously.

In this paper, we propose a general modeling approach: 1) There are two competing firms: one is an e-tailer which sells the product online directly and another one is a retailer which sells the product through the brick-mortar retailing store. The objectives of these two firms are to maximize their own profits, respectively. 2) The asymmetric choice of quantity commitment is adopted: it is assumed that the e-tailer never makes a quantity commitment because of its shortened lead times, or else it adopts just-in-time systems to circumvent quantity commitment while the retailer can choose to make the quantity commitment or not. This kind of model is common. For example, Dell Company which sells many of its products online normally does not make quantity commitment; rather it starts production only when the demand from consumers is received while its retailing competitor does (Guo and Iyer 2013). Dell's approach constitutes a pull system in terms of supply chain strategy. In contrast, the competitors are employing a push supply chain strategy. The push versus pull system and level of quantity commitment has an impact on the supply chain business function known as 
"available to promise" (ATP). Push-based ATP is based on forecasts of future demand which can be inaccurate. Pull-based systems dynamically allocate resources in response to actual customer demand (Zhao 2005). 3) Heterogeneous consumers value the product differently. On the market, they are uniformly distributed on the interval $[0,1]$ and have a total mass of 1 . This kind of consumer distribution is widely adopted and in common knowledge (Kabul and Parlaktürk 2017). 4) Firms will strategically set the prices at a subsequent stage regardless of whether it commits to a quantity or not in the earlier stage. They compete against each other.

Our study incorporates the difference between online and brick-mortar retailing sales into the model, which is widely discussed in the literature. The seminal work mainly demonstrates the main differences in the following aspects: 1) online sales require longer delivery times and additional shipping and handling fees (Hess, Gerstner and Chu 1996); 2) brick-mortar retail sales are more convenient (Liang and Huang 1998); and 3) there is less consumer acceptance of the product value through online purchases (Kacen, Hess and Chiang 2013; Chiang, Chhajed and Hess 2003 and Qin and Mambula 2018). In our study, we adopt the model of Chiang, Chhajed and Hess (2003) and assume that a consumer acceptance of online channel is $\theta$ due to the difference between the online and brick-mortar retail sales. Moreover, Chiang et al. (2003) further adopt that the acceptance of the online channel by consumers is $\theta(0<\theta<1)$, i.e., $1-\theta$ is the proportionate loss of benefits from an online channel purchase.

In practice, Nasser and Turcic (2016) show that on one hand, there are lots of mechanisms which lead the firms to be constrained to the committed quantity, including the plant capacity which limits the quantity for the firm to produce and ultimately sell, warehouse and shelf capacities to limit the quantity of items for the firm to stock, and long replenishment lead times to constrain the quantity of the items for the seasonal goods sellers if the initial inventory cannot be replenished. On the other hand, there are lots of mechanisms for the firm not to be constrained to the committed quantity including matching supply with demand by investing in large capacities, shortening lead times, or adopting just-in-time systems. For instance, Dell starts the production only when the demand from consumers is received (Guo and Iyer 2013). A firm's decision on whether or not to commit to a quantity directly affects the firm's profit and further its success in the market. This is more important when firms compete in the market and the quantity commitment can mitigate the price competition, which is part of the motivation for our work. Specifically, we investigate whether the retailer will make the quantity commitment or not in the decentralized supply chain.

We find that the retailer always chooses to commit to a specific quantity in equilibrium regardless of the product differentiation from the two firms when the retailer and e-tailer are in a decentralized supply chain. This result demonstrates that quantity commitment is popular when firms are in competition and it allows both firms to mitigate intense price competition. This result closes the gap in the extant literature and sheds more lights on the asymmetric quantity commitment since the adoption of the asymmetric quantity commitment does not depend on the product differentiation degree, which is different from the results from Nasser and Turcic (2016) who shows that its adoption depends on the product differentiation degree to some extent.

We derive the results by analyzing a multi-stage game. In the first stage of the game, the retailer chooses whether or not to commit to a quantity and the specific committed quantity if it chooses to commit. In the second stage, both the retailer and e-tailer set prices strategically, regardless of whether or not the retailer commits to a quantity earlier in the first stage. In the final stage, consumers choose the product among the two firms to maximize their own utilities and demand is realized for the retailer and e-tailer, respectively, where the e-tailer can fulfill any quantity that consumers demand at the equilibrium prices while the retailer can only fulfill the committed quantity if it commits earlier in the first stage or it can also fulfil any quantity that consumers demand if it does not commit earlier.

The rest of the paper is organized as follows: Literature related to previous research is demonstrated following "Introduction", then models and results are demonstrated and shown following "Literature". The final Section presents the conclusions. 


\section{LITERATURE}

Our work is related to quantity commitment. The earliest and most famous work in this area is the Cournot model which assumes that the firm sells the entire committed quantity at the price that will clear such a quantity. Further Kreps and Scheinkman (1983) show that the Cournot model is similar to assuming the presence of an auctioneer. They demonstrated it by formulating a model in which firms play in a two-stage game, where the firms commit to a quantity in the first stage and set the prices in the second stage. They show that the two-stage game yields the same outcomes as that of the Cournot model. Although their work is a breakthrough in understanding quantity commitment, they do not show the firms' incentives to commit to a quantity. Following that, Nasser and Turcic (2016) show that Cournot outcomes are not necessarily yielded in a committed quantity scenario if firms set the prices strategically in a Hoteling model. In contrast to Nasser and Turcic (2016), we focus on the model in which only one firm makes a decision whether to commit to the quantity or not while the other one, which shortens lead times, or adopts just-in-time systems to circumvent quantity commitment, does not make a quantity commitment where the heterogeneous consumers are uniformly distributed. Our results are different from Nasser and Turcic (2016): Nasser and Turcic (2016) showed the limitation to adopt the asymmetric quantity commitment, that is, only when the product differentiation is high to some extent. It is not clear that whether it is better off or not to adopt the asymmetric quantity commitment when the product differentiation is high beyond the extent. Our study closes the gap in the extant literature by showing that the adoption of the asymmetric quantity commitment does not depend on the product differentiation from the competing firms.

Regarding that only one firm considers the quantity commitment, the seminal work includes Daughety (1990), Shulman (2014) and Allen, Faith and Kovenoc (2000). Among them, Daughety (1990) shows that the Stackelberg game makes the leader commit to a greater quantity compared to the simultaneous game. Shulman (2014) demonstrates that the firm commits to a lesser quantity while the unconstrained competitor sells a greater quantity than in the no-quantity commitment. Allen, Faith and Kovenoc (2000) shows that a quantity commitment can act as a barrier to entry. Our study is similar to these seminal works and focuses on the scenario where one firm makes a decision whether to commit to the quantity or not in the competition with another firm which does not make quantity commitment. But our objective is to investigate the effect of quantity commitment on the firm's profit, i.e., whether the quantity commitment can make the firm earn a higher profit in the competition with another firm and finally help the firm make the decision whether the quantity commitment should be made or not.

Our work is also related to the research stream of the competition between direct and retailing sales. In the previous research, Balasubramanian (1998) considers the market coverage as a lever to control competition. Tsay and Agrawal (2004) and Chiang, Chhajed, and Hess (2003) extend the competition to the setting where one party in the competition is not only the supplier to but also the competitor of another one, which has been observed in industry. Our work adopts the market coverage as a lever in the competition. The study also considers the case that both parties in the competition belong to the integrated firm, which is similar to Tsay and Agrawal (2004) and Chiang, Chhajed, and Hess (2003). In summary, our work extends the literature related to the quantity commitment problem by addressing the following research questions: How does the asymmetric quantity commitment affect the pricing strategies and further the profits of brick-mortar retailing store (retailer) and e-tailing store (e-tailer) in the competition? We analyze the incentives for the brick-mortar retailing store to make a quantity commitment to compete with the e-tailer, and conclude that asymmetric quantity commitment helps mitigate the price competition and increase profits of both parties. Therefore, the retailer adopts the quantity commitment to improve the profit in a decentralized supply chain. 
Table 1. Modeling parameter notation

\begin{tabular}{|cl|}
\hline Parameter & Description \\
\hline$r$ & index of the retailer \\
\hline$e$ & index of the e-tailer \\
\hline$c$ & index of commitment for the retailer's decision on the product quantity \\
\hline$n$ & index of no commitment for the retailer's decision on the product quantity \\
\hline$\theta$ & customer acceptance of the Internet channel \\
\hline$v$ & valuation of the product \\
\hline$\omega$ & equilibrium mixing probability for the e-tailer \\
\hline
\end{tabular}

\section{MODEL SETUP}

We consider two competing firms that sell the product to heterogeneous consumers. Among these two competing firms are the e-tailer which sells the good on the Internet and the traditional bricksand-mortar retailing store which is called a retailer for brevity in this study.

Consumers are heterogeneous in the valuation of the product which is denoted by $v$. For analytic simplicity, it is assumed that the valuation of the product is uniformly distributed within the consumer population from 0 to 1 , within a density of 1 (Chiang, Chhajed, and Hess).

Although these two competitors sell the product, the valuations of the product are different from the point view of the consumers. Chiang, Chhajed, and Hess (2003) adopts $\theta$ to represent the customer acceptance of the online channel. In more detail, the product is worth $\theta v$ if purchased from the e-tailer due to the lack of a real inspection and immediate possession, compared to being worth $v$ if purchased from the retailer. The customer acceptance can be further justified by the following seminal work: Liang and Huang (1998) show that overall, consumers prefer to purchase from the retailer rather than web-based direct channels. The study from Kacen et al. (2013) demonstrates that the customer acceptance of the Internet-based purchases is less than one for many product categories, i.e., most Internet-based purchases are less valuable compared to those from the retailer. In this study, the model is developed for those products with $0<\theta<1$ which is similar to the work in Chiang et al. (2003). It is assumed that the marginal cost of the product is normalized to zero.

In our model, we use $r$ and $e$ to represent the retailer and e-tailer, respectively. $c$ and $n$ are used to represent the case that the retailer makes a quantity commitment, and the case that the retailer does not make a quantity commitment, respectively. $\omega$ is used to represent the equilibrium probability that the e-tailer will adopt the optimal price $\underline{p}_{e}$ when the retailer's total served demand is less than the committed quantity $q_{r}$ in the mixing equilibrium. The model parameters are summarized in Table 1 .

In our model, the retailer first makes decisions on whether to make a quantity commitment or not, if yes, then what is the committed quantity? Following that, both of the retailer and e-tailer make their own decisions on price, respectively. These decisions affect their respective demand from the market and finally their own profits. The variables that represent the retailer and e-tailer's decisions and further their demand and profits are summarized in Table 2, respectively.

Based on Table 2, the optimal decision variables are listed in Table 3. 
Table 2. Modeling variable notation

\begin{tabular}{|cc|}
\hline Variable & Description \\
\hline$q_{r}$ & retailer's committed quantity \\
\hline$p_{r}^{n}$ & price of the product sold by the retailer without quantity commitment \\
\hline$p_{e}^{n}$ & price of the product sold by the e-tailer without quantity commitment \\
\hline$p_{r}$ & price of the product sold by the retailer with quantity commitment \\
\hline$p_{e}$ & price of the product sold by the e-tailer with quantity commitment \\
\hline$D_{r}^{n}$ & demand for the retailer without quantity commitment \\
\hline$D_{e}^{n}$ & demand for the e-tailer without quantity commitment \\
\hline$D_{r}$ & demand for the retailer with quantity commitment \\
\hline$D_{e}$ & demand for the e-tailer without quantity commitment \\
\hline$\pi_{r}^{n}$ & retailer's profit without quantity commitment \\
\hline$\pi_{e}^{n}$ & e-tailer's profit without quantity commitment \\
\hline$\pi_{r}$ & retailer's profit with quantity commitment \\
\hline$\pi_{e}$ & e-tailer's profit with quantity commitment \\
\hline
\end{tabular}

\section{DEMAND IN BOTH THE E-TAILER AND RETAILER CHANNELS}

We now proceed to the demand in both the e-tailer and retailer channels. Let us show the demands in details for the case that the retailer makes a quantity commitment in the decentralized supply chain. The demands in other cases are similar except that the notations of the decision variables in the model are different. If the product is purchased from the e-tailer at a price $p_{e}$ and the valuation of the product is $\theta v$, then the consumer surplus is $\theta v-p_{e}$ while if the product is purchased through the retailer at a price $p_{r}$, then the consumer surplus is $v-p_{r}$. Whether the consumer purchases the product through the e-tailer or through the retailer depends on the higher consumer surplus. Therefore, the consumer whose valuation equals $\frac{p_{r}-p_{e}}{1-\theta}$ is indifferent to purchasing from either the e-tailer or the retailer. Therefore, if their valuations of the product exceed $\frac{p_{r}-p_{e}}{1-\theta}$, consumers prefer the purchase from the retailer; otherwise, they prefer from the e-tailer. From Chiang et al. (2003), it is known that the demand for the retailer and e-tailer is as follows, respectively:

$$
D_{r}=\left\{\begin{array}{lr}
1-\frac{p_{r}-p_{e}}{1-\theta} & \text { if } \frac{p_{e}}{\theta} \leq p_{r} \\
1-p_{r} & \text { otherwise }
\end{array}\right.
$$

and: 
Table 3. Modeling optimal decision variable notation

\begin{tabular}{|cc|}
\hline Variable & Description \\
\hline$q_{r}{ }^{*}$ & retailer's optimal committed quantity \\
\hline$p_{r}^{n^{*}}$ & optimal price of the product sold by the retailer without quantity commitment \\
\hline$p_{e}^{n^{*}}$ & optimal price of the product sold by the e-tailer without quantity commitment \\
\hline$p_{r}^{*}$ & optimal price of the product sold by the retailer with quantity commitment \\
\hline $\bar{p}_{e}$ & demand is $q_{r}$ \\
\hline$\underline{p}_{e}$ & optimal price of the product sold by the e-tailer when the retailer's total served demand \\
\hline$p_{e}{ }^{*}$ & is less than $q_{r}$
\end{tabular}

$D_{e}=\left\{\begin{array}{lr}\frac{\theta p_{r}-p_{e}}{\theta(1-\theta)} & \text { if } \frac{p_{e}}{\theta} \leq p_{r} \\ 0 & \text { otherwise }\end{array}\right.$

The demands of the retailer and e-tailer are further shown in Figure 1 when $\frac{p_{e}}{\theta} \leq p_{r}$ and Figure 2 when $\frac{p_{e}}{\theta}>p_{r}$ (otherwise).

In Figure 1, if, $w^{*}$ hen the product value is between and, the customers will buy the product from the e-tailer and the demand for the e-tailer equals while when the product value is between and 1 , they will buy from the retailer and the demand for the retailer equals.

In Figure 2, if there are no customers to buy the product from the e-tailer since no product value satisfies both higher than $\frac{p_{e}}{\theta}$ and lower than $\frac{p_{r}-p_{e}}{1-\theta}$ and therefore the demand for the e-tailer equals zero while when the product value is between $p_{r}$ and 1 , they will buy from the retailer and the

Figure 1. The demands $D_{r}$ and $D_{e}$ for both channels, respectively when $\frac{p_{e}}{\theta} \leq p_{r}$

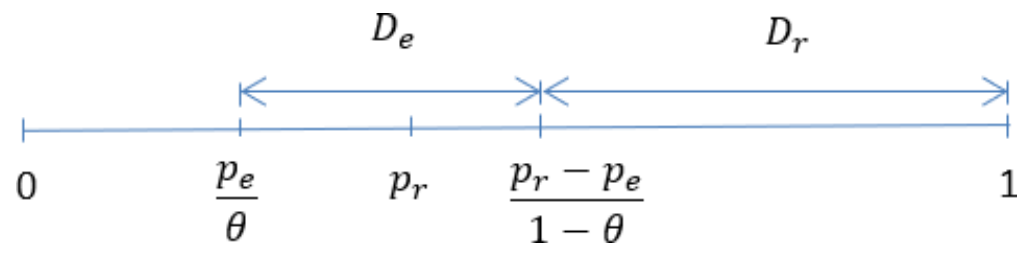


Figure 2. The demands $D_{r}$ and $D_{e}\left(D_{e}=0\right)$ for both channels, respectively when $\frac{p_{e}}{\theta}>p_{r}$

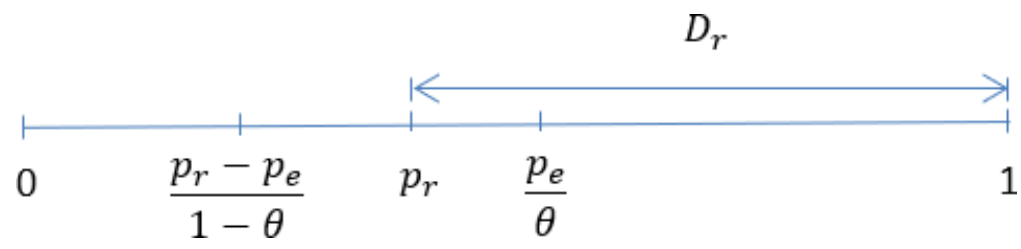

demand for the retailer equals $1-p_{r}$. From the demand functions in both channels, it can be seen that the e-tailer can still appeal to some consumers when the price of the retailer is high even though the customer acceptance of the e-tailer channel discounts the valuation of the product.

Before the e-tailer and retailer sell the products, the retailer chooses whether or not to commit to a quantity. If the retailer chooses to commit to a quantity $q_{r}$ which represents either the retailer's in-house production capacity or the quantity it has to preorder prior to selling, the retailer cannot sell more than the committed quantity $q_{r}$. If the retailer chooses not to commit to a quantity, it can fulfill any demand that arises after both parties set their prices, respectively. The e-tailer always fulfills any demand to arise that follows the announced prices from both parties.

After the retailer's decisions on the commitment and the quantity, the e-tailer and the retailer set the selling prices strategically. Following the prices from the e-tailer and the retailer, respectively, the demand is achieved in each channel, which is denoted by $D_{i}^{n}\left(p_{i}^{n}, p_{j}^{n}\right)$ when the retailer makes no quantity commitment and denoted $D_{i}\left(p_{i}, p_{j}\right)$ when the retailer makes quantity commitment, where $i, j \in\{r, e\}: i \neq j$.

And the retailer and e-tailer set their own prices to maximize their own profit as follows, respectively:

When the retailer chooses to commit to a quantity $q_{r}$ :

$\max _{p_{r}} \pi_{r} \equiv p_{r} D_{r}\left(p_{r}, p_{e}\right)$

subject to:

$D_{r}\left(p_{r}, p_{e}\right) \leq q_{r}$

$\max _{p_{e}} \pi_{e} \equiv p_{e} D_{e}\left(p_{r}, p_{e}\right)$

Equation (3) shows that the retailer's profit $\pi_{r}$ is the product of the price $p_{r}$ and demand $D_{r}\left(p_{r}, p_{e}\right)$ which is the function of $p_{r}$ and $p_{e}$ shown in Equation (1). Moreover, the retailer's demand is constrained by the committed quantity $q_{r}$, that is, the demand is no more than $q_{r}$. 
Equation (4) shows that the e-tailer's profit $\pi_{e}$ is the product of the price $p_{e}$ and demand $D_{e}\left(p_{r}, p_{e}\right)$ which is the function of $p_{r}$ and $p_{e}$ shown in Equation (2).

2. When the retailer chooses not to commit to any quantity:

$$
\max _{p_{r}^{n}} \pi_{r}^{n} \equiv p_{r}^{n} D_{r}^{n}\left(p_{r}^{n}, p_{e}^{n}\right)
$$

$$
\max _{p_{e}^{n}} \pi_{e}^{n} \equiv p_{e}^{n} D_{e}^{n}\left(p_{r}^{n}, p_{e}^{n}\right)
$$

Equations (5) and (6) show the retailer and e-tailer's profits, respectively when the retailer does not commit to any quantity. The expressions in (5) and (6) are similar to those in (3) and (4), respectively. The only difference is that the retailer's demand in (5) is not constrained by any quantity.

To explore the results in Equations (3), (4), (5) and (6), the assumptions in Section 3.2 are adopted and details of the results are shown in Section 4.

\section{ADDITIONAL ASSUMPTIONS}

Our study adopts the following assumptions (Nasser and Turcic, 2016):

1. Efficient rationing: As we discuss in Subsection 3.1, when the retailer chooses to commit to a quantity, it imposes a constraint on the number of consumers the retailer can serve, which may lead to product shortages, that is to say, the number of the consumers who prefer to purchase the product from the retailer exceeds the quantity to which the retailer has committed earlier. In this case, we assume that the inventory will be cleared by the consumers who achieve a higher utility for the product. This rule is efficient with the maximization of the consumer surplus (see Kreps and Scheinkman, 1983).

2. Tie-breaking quantity decision: If the retailer chooses to commit to a quantity and can achieve the same profit under multiple order quantities, it is assumed that the retailer will choose the smallest quantity.

\section{GAME SEQUENCE}

In this subsection, we show the sequence of the stages in the game between the e-tailer and retailer in our study as follows:

Stage 1: The retailer chooses whether or not commit to a quantity. If yes, it sets the quantity/capacity, $q_{r}$.

Stage 2: The selling stage begins and both the e-tailer and the retailer choose their own prices to maximize their own profits.

Stage 3: Based on the surplus of the product, each consumer chooses whether or not to buy and from which channel to buy. 
The sequence shows that the two firms follow a multi-stage game of perfect information. Backward induction is used in the analysis. To the best of our knowledge, the seminal work to endogenize the decision of whether or not to commit includes Singh and Vives (1984) and Nasser and Turcic (2016). In their study, commitment is observable, which is consistent with our work in the game sequence presented above.

\section{SUBGAME ANALYSIS}

We analyze the subgames of Stages 2-3 conditional on whether the retailer makes the quantity commitment decision in Stage 1 or not. Then we explore the decision in Stage 1 for the retailer to commit or not and if committing, what is the optimal committed quantity?

\section{NO COMMITMENT FOR THE RETAILER'S DECISION ON THE PRODUCT QUANTITY}

First suppose that the retailer makes no commitment on the product quantity in Stage 1. Following Stage 1, the e-tailer and the retailer announce their own prices to maximize their own profits, respectively. As discussed earlier, there are no quantity constraints for the demand when the retailer makes no quantity commitment.

Based on the demands shown in Figures 1 and 2, simultaneously solving the first-order conditions (FOCs) of the retailer's and the e-tailer's objective functions shown in (5) and (6) yields the following equilibrium price and profits (see Figure 3):

$$
p_{r}^{n^{*}}=\frac{2(1-\theta)}{4-\theta}
$$

and:

$$
p_{e}^{n^{*}}=\frac{\theta(1-\theta)}{4-\theta}
$$

Then:

$$
\begin{gathered}
\pi_{r}^{n}=\frac{4(1-\theta)}{(4-\theta)^{2}} \\
\pi_{e}^{n}=\frac{\theta(1-\theta)}{(4-\theta)^{2}}
\end{gathered}
$$

Figure 3 shows the intersection point of the best pricing response functions from the retailer and e-tailer which represents the optimal price equilibrium. 
Figure 3. Best pricing response functions under no quantity commitment (Note: the dotted line represents the best pricing response functions from the retailer and e-tailer, respectively)

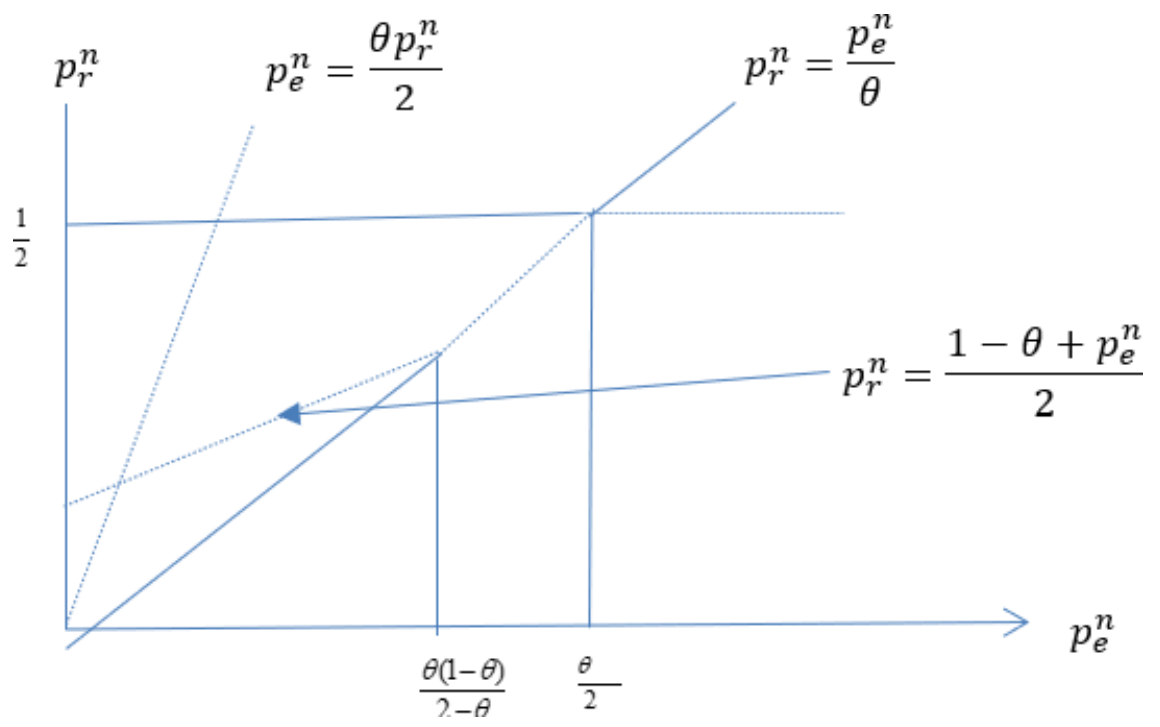

\section{COMMITMENT FOR THE RETAILER'S DECISION ON THE PRODUCT QUANTITY}

Next suppose that the retailer commits to a quantity $q_{r}$ in Stage 1 . Then the retailer's demand will be constrained by the quantity $q_{r}$ and the total demand served by the e-tailer is unconstrained. We proceed with the analysis by first solving the equilibrium prices in Stage 2. Then we solve for the retailer's equilibrium quantity in Stage 1.

LEMMA 1: The retailer's committed quantity $q_{r} \leq \frac{1}{2}$.

Lemma 1 shows us the range of the committed quantity if the retailer makes a commitment. Based on Lemma 1, our study focuses on the retailer's committed quantity $q_{r} \leq \frac{1}{2}$.

\section{EQUILIBRIUM RESULTS}

When $q_{r} \leq \frac{1}{2}$, the best pricing response functions from the retailer and e-tailer, respectively are presented in Figure 4 by the dotted lines. If $p_{e} \leq \theta\left(1-q_{r}\right)$, the retailer will choose the optimal price $p_{r}=(1-\theta)\left(1-q_{r}\right)+p_{e}$. In this scenario, the retailer and the e-tailer will always compete and the total demand served by the retailer is $q_{r} \leq \frac{1}{2}$. However, if $p_{e}>\theta\left(1-q_{r}\right)$, the retailer will choose the optimal price $p_{r}=1-q_{r}$. In this case, the e-tailer will be forced to be out of the market. Only the retailer serves the market with the total demand $q_{r}$. By contrast, when $0 \leq p_{r}<\sqrt{1-\theta}\left(1-q_{r}\right)$, 
the e-tailer chooses the optimal price $p_{e}=\frac{\theta\left(1-q_{r}\right)}{2}$; when $p_{r} \geq \sqrt{1-\theta}\left(1-q_{r}\right)$, the e-tailer chooses the optimal price $p_{e}=\frac{\theta p_{r}}{2}$.

The following result characterizes the subgame equilibrium prices conditional on all possible values of $q_{r} \leq \frac{1}{2}$.

When $p_{e}=\frac{\theta p_{r}}{2}$, the e-tailer's profit is as follows:

$\pi_{e}=\frac{\theta p_{r}{ }^{2}}{4(1-\theta)}$

when $p_{e}=\frac{\theta\left(1-q_{r}\right)}{2}$, e-tailer's profit is as follows:

$\pi_{e}=\frac{\theta\left(1-q_{r}\right)^{2}}{4}$

Therefore, when $p_{r}>\sqrt{1-\theta}\left(1-q_{r}\right), \quad p_{e}^{*}=\frac{\theta p_{r}}{2}$ while when $p_{r}<\sqrt{1-\theta}\left(1-q_{r}\right)$, $p_{e}^{*}=\frac{\theta\left(1-q_{r}\right)}{2}$ and when $p_{r}=\sqrt{1-\theta}\left(1-q_{r}\right)$, either $p_{e}^{*}=\frac{\theta p_{r}}{2}$ or $p_{e}^{*}=\frac{\theta\left(1-q_{r}\right)}{2}$. The results can be summarized in Propositions 1 and 2 .

In Figure 4, there is no actual intersection point by the best price response functions from both the retailer and e-tailer. When the retailer's price $p_{r}{ }^{*}=\sqrt{1-\theta}\left(1-q_{r}\right)$, the e-tailer's best price response can be either $\bar{p}_{e}=\frac{\theta\left(1-q_{r}\right)}{2}$ or $\underline{p}_{e}=\frac{\theta p_{r}}{2}$, which creates the mixed strategy equilibrium.

PROPOSITION 1: There is no pure strategy equilibrium and only mixed strategy equilibrium exists as follows.

The e-tailer plays $p_{e}^{*}=\underline{p}_{e}$ with probability $\omega$ and $p_{e}^{*}=\bar{p}_{e}$ with probability $1-\omega$, where:

$$
\begin{aligned}
& \omega=\frac{q_{r} \sqrt{1-\theta}}{(2-\theta-\sqrt{1-\theta})\left(1-q_{r}\right)} \\
& p_{r}^{*}=\sqrt{1-\theta}\left(1-q_{r}\right)
\end{aligned}
$$

and: 
Figure 4. Best pricing response functions under commitment of $q_{r} \leq \frac{1}{2}$ (Note: the dotted line represents the best pricing response functions from the retailer and e-tailer, respectively)

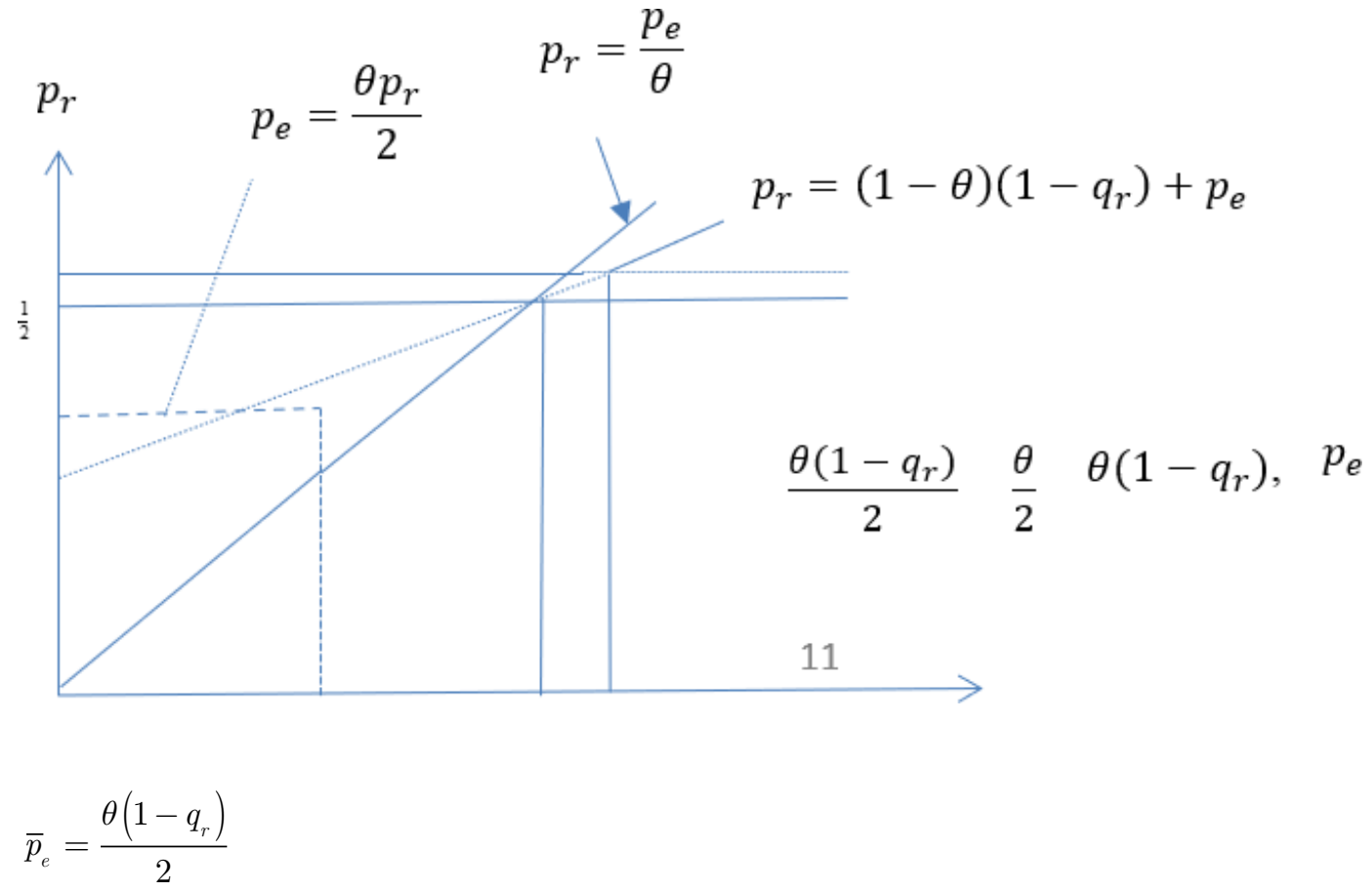

or:

$p_{r}^{*}=\sqrt{1-\theta}\left(1-q_{r}\right)$

and:

$\underline{p}_{e}=\frac{\theta p_{r}}{2}$

In this mixed strategy equilibrium, when the e-tailer randomizes between $\underline{p}_{d}$ and $\bar{p}_{d}$ with probabilities $\omega$ and $1-\omega$, respectively, the brick-mortar retailer serves the demand:

$$
\frac{2 \sqrt{1-\theta}-\left(1-q_{r}\right)(2-\theta)}{2 \sqrt{1-\theta}}
$$

which is less than the committed quantity $q_{r}$ with the probability $\omega$ and the demand which is equal to the committed quantity $q_{r}$ with the probability $1-\omega$. 
PROPOSITION 2: When the retailer makes the quantity commitment, the optimal committed quantity $q_{r}^{*}=\frac{1}{2}$. Following that, the profits of the retailer and e-tailer are as follows, respectively:

$\pi_{r}=\frac{(2-\theta) \sqrt{1-\theta}}{8(2-\theta-\sqrt{1-\theta})}$

$\pi_{e}=\frac{\theta}{16}$

\section{THE RETAILER'S DECISION IN THE QUANTITY COMMITMENT}

In Stage 1, the retailer needs to make the decision whether to commit to the quantity or not. The objective of the retailer is to maximize its own profit. Based on the comparison between (9) and (13), Proposition 3 is shown as follows:

PROPOSITION 3: See below:

1. $p_{r}^{n^{*}}<p_{r}^{*}$ and $p_{e}^{n^{*}}<p_{e}^{*}$

2. $\pi_{r}^{n}<\pi_{r}$, therefore the retailer always chooses to commit to the quantity

3. $\pi_{e}^{n}<\pi_{e}$

Proposition 3 shows us that the commitment quantity can always help mediate the price competition and therefore both the retailer and e-tailer achieve higher profits in the competing environment under asymmetric quantity commitment compared to no quantity commitment. This result sheds light on the justification of the widely adopted asymmetric quantity commitment in the retailing practice, for instance, Dell computer company, Zara fashionable clothing company and most recent developments on quantity commitment and lead-time management (den Bosshe et al. 2014). This results also contribute to the extant literature: The results from Nasser and Turcic (2016) showed the limitation to adopt the asymmetric quantity commitment, that is, only when the product differentiation from two competing firms is high to some extent. It is not known whether it is better off to adopt the asymmetric quantity commitment when the product differentiation is high beyond the extent. Our results show that the asymmetric quantity commitment should always be adopted regardless of the product differentiation from the competing firms in our presented scenario. These results are in accordance with our intuition: when one firm can provide an unlimited quantity to meet the demand, the competing firm will always make a quantity commitment to mitigate the competition and therefore both parties benefit from the quantity commitment due to the competition mitigation.

\section{CONCLUSION}

In this study, we focus on the mechanisms of committing to a quantity or not which are of strategic importance. In more details, we focus on the asymmetric quantity commitment choices which are common in the retailing practice. For example, Dell computer company avoids quantity commitment through its flexible just-in-time manufacturing operation while most of its competitors do not (Guo and 
Iyer 2013). Zara, a fashion clothing company, is another typical example which overcomes quantity commitment through slashing lead time via a fast supply chain while most of its competitors do not (Ferdows et al. 2004, Caro and Martinez-de-Albeniz 2010). Adidas is employing technology such as $3 \mathrm{D}$ printing, robotics, and computerized knitting to offer mass personalization of running shoes at the retail level. Adidas calls this deployment a speed factory and represents an ultimate form of the supply chain strategy known as product differentiation postponement. This strategy at the bricks and mortar retail level does not require a quantity commitment of the end-item running shoes (Wiener 2017). Furthermore, den Bosshe et al. (2014) make a survey to show the most recent developments on quantity commitment and lead-time management.

The objective of our study is to demonstrate the incentives of asymmetric quantity commitment when retailer and e-tailer sell the same or similar products which are valued differently among consumers. The multi-stage game is analyzed. In Stage 1, the retailer makes the decision on quantity commitment or not and if yes, determines the committed quantity. In Stage 2, both firms set prices strategically to maximize their own profits regardless of whether the retailer makes a quantity commitment or not. In the last stage, consumers make the decision to buy the product or not and from which firm to buy in order to maximize their surplus. Therefore, the demand is allocated to both channels. Lastly the consumers make the choice to buy and demand is allocated in each channel.

We find that 1) the asymmetric quantity commitment always helps the firms- both the retailer and e-tailer achieve higher profits. Our findings highlight the effect of the managerial decision of whether or not to commit to a quantity given the competitive nature of the company. These findings also provide an explanation as to why the asymmetric quantity commitment is ubiquitous when the flexible regimes and/or just-in-time that can circumvent quantity commitment is becoming more and more popular. 2) These findings also provide supplemental results for asymmetric quantity commitment in the study by Nasser and Turcic (2016). In their study, they show the conditions for the asymmetric quantity commitment to be adopted to mitigate the price competition, which means asymmetric quantity commitment does not always help mitigate price competition in their study. However, our results from this study of the scenario demonstrate that asymmetric quantity commitment may always be adopted since it always helps mitigate the price competition and further achieve higher profits.

On the research front, we hope that this paper invites others to investigate the topic further. For example, we assume the demand is normalized to one. Whether the demand uncertainty has an effect on the decision of quantity commitment or not is a potential question in the future research. 


\section{REFERENCES}

Allen, B., Deneckere, R., Faith, T., \& Kovenoc, D. (2000). Capacity precommitment as a barrier to entry, a Bertrand-Edgeworth analysis. Economic Theory, 15(3), 501-530. doi:10.1007/s001990050309

Balasubramanian, S. (1998). Mail versus mall: A strategic analysis of competition between direct marketers and conventional retaiers. Marketing Science, 17(3), 181-195. doi:10.1287/mksc.17.3.181

Caro, F., \& Martinez-de-Albeniz, V. (2010). The impact of quick response in inventory-based competition. Manufacturing \& Service Operations Management, 12(3), 409-429. doi:10.1287/msom.1090.0274

Chiang, W. Y., Chhajed, J., \& Hess, D. (2003). Direct marketing, indirect profits: A strategic analysis of dualchannel supply-chain design. Management Science, 49(1), 1-20. doi:10.1287/mnsc.49.1.1.12749

Daughety, A. F. (1990). Beneficial concentration. The American Economic Review, 80(5), 1231-1237.

Ferdows, K., Lewis, M. A., \& Machuca, J. A. D. (2004). Rapid-fire fulfillment. Harvard Business Review, 11, 1-7.

Guo, L., \& Iyer, G. (2013). Multilateral bargaining and downstream competition. Marketing Science, 32(3), 411-430. doi:10.1287/mksc.1120.0766

Hess, J., Gerstner, E., \& Chu, W. (1996). Controlling product returns in direct marketing. Marketing Letters, 7(4), 307-317. doi:10.1007/BF00435538

Kabul, M. O., \& Parlaktürk, A. K. (2017). Value of commitments when selling to strategic consumers: A Supply Chain Perspective. Working paper, University of North Carolina-Chapel Hill.

Kacen, J., Hess, J., \& Chiang, W. K. (2013). Bricks or clicks? Consumer attitudes toward traditional stores and online stores. Global Economics and Management Review, 18(1), 12-21. doi:10.1016/S2340-1540(13)70003-3

Kreps, D., \& Scheinkman, J. (1983). Quantity precommitment and Bertrand competition yields Cournot outocmes. The Bell Journal of Economics, 14(2), 326-337. doi:10.2307/3003636

Liang, T., \& Huang, J. (1998). An empirical study on consumer acceptance of products in electronic markets: A transaction cost model. Decision Support Systems, 24(1), 29-43. doi:10.1016/S0167-9236(98)00061-X

Nasser, S., \& Turcic, D. (2016). To commit or not to commit: Revisiting quantity vs. price competition in a differentiated industry. Management Science, 62(6), 1719-1733. doi:10.1287/mnsc.2015.2213

Qin, Z., \& Mambula, C. J. (2018). Price timing by e-tailer and brick-mortar retailer in new markets with strategic consumers. International Journal of Applied Management Science, 10(1), 72-85. doi:10.1504/ IJAMS.2018.089952

Shulman, J. D. (2014). Product diversion to a direct competitor. Marketing Science, 33(3), 422-436. doi:10.1287/ mksc.2013.0816

Singh, N., \& Vives, X. (1984). Price and quantity competition in a differentiated duopoly. The RAND Journal of Economics, 15(4), 546-554. doi:10.2307/2555525

Tsay, A., \& Agrawal, N. (2004). Channel conflict and coordination in the E-commerce age. Production and Operations Management, 13(1), 93-110. doi:10.1111/j.1937-5956.2004.tb00147.x

Van den Bosshe, P., Gupta, P., Gutierrez, H., \& Gupta, A. (2014). Solving the reshoring dilemma. Supply Chain Management Review, 18(1), 26-33.

Wiener, A. (2017). Inside Adidas's Robot-Powered, on Demand Sneaker Factory. Wired.Com. December Issue.

Zhao, Z., Ball, M. O., \& Kotake, M. (2005). Optimization-based Available-to-promise with Multi Stage Resource Availability. Annals of Operations Research, 135(1), 65-85. doi:10.1007/s10479-005-6235-7 


\section{APPENDIX}

PROOF OF LEMMA 1: When $q_{r}>\frac{1}{2}$, the best pricing response functions are shown in Figures $5(\mathrm{a})$ and 5(b).

From Figure 5(a), it is clear that when $\frac{1}{2}<q_{r} \leq 1-\frac{2 \sqrt{1-\theta}}{4-\theta}$, the mixing equilibrium exists and achieves the same outcomes as in Figure 4, that is to say, the optimal results can be achieved when $q_{r} \leq \frac{1}{2}$. According to the assumption of the tie-breaking quantity decision, the retailer will not choose $q_{r}>\frac{1}{2}$. In Figure 5(b), the equilibrium exists and achieves the same outcomes as in Figure 3. There is no advantage for the retailer to make quantity commitment to achieve a higher profit.

Combining the results from Figures 5(a) and 5(b), the retailer makes commitment to a quantity $q_{r} \leq \frac{1}{2}$

PROOF OF PROPOSITION 1: The e-tailer plays $p_{e}{ }^{*}=\underline{p}_{e}$ with probability $\omega$ and $p_{e}{ }^{*}=\bar{p}_{e}$ with probability $1-\omega$, where:

Figure 5. Best pricing response functions under commitment when $\frac{1}{2}<q_{r} \leq 1-\frac{2 \sqrt{1-\theta}}{4-\theta}$ (Note: the dotted line represents the best pricing response functions from the retailer and e-tailer, respectively)

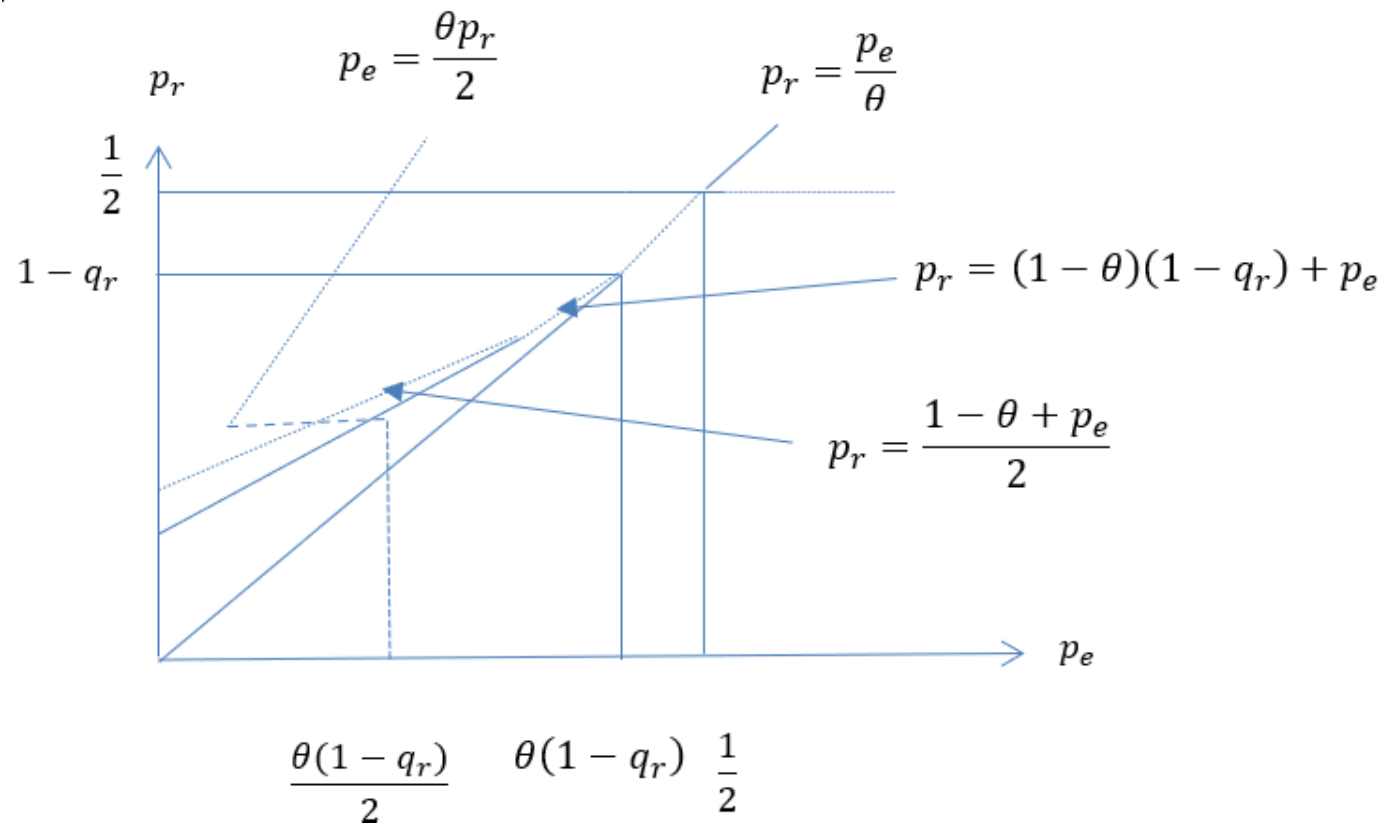


Figure 6. Best pricing response functions under commitment of $1-\frac{2 \sqrt{1-\theta}}{4-\theta}<q_{r} \leq 1$ (Note: the dotted line represents the best pricing response functions from the retailer and e-tailer, respectively)

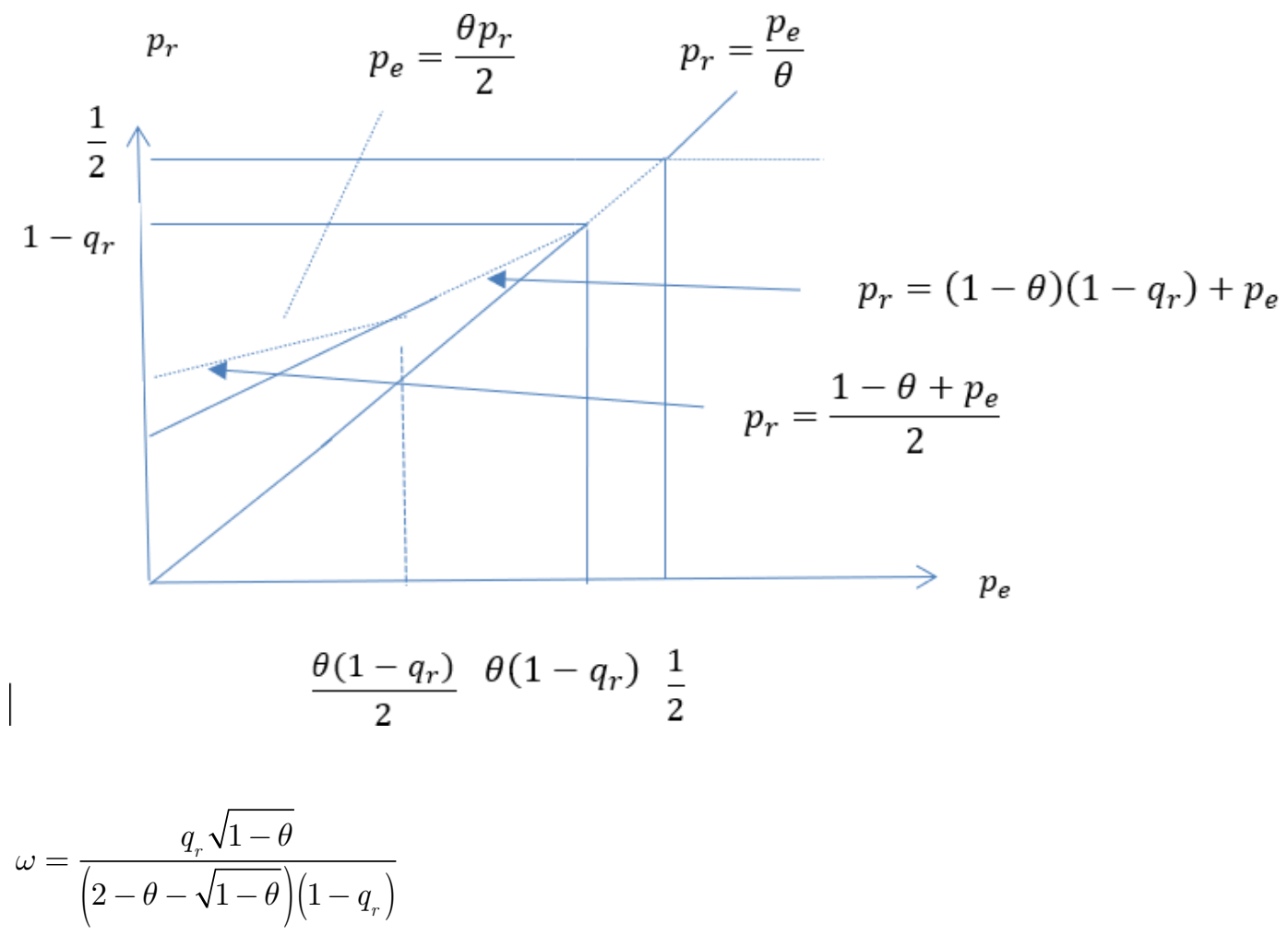

since the e-tailer achieves the same profit when:

1. $p_{r}=\sqrt{1-\theta}\left(1-q_{r}\right)$ and $\bar{p}_{e}=\frac{\theta\left(1-q_{r}\right)}{2}$; and

2. $p_{r}=\sqrt{1-\theta}\left(1-q_{r}\right)$ and $\underline{p}_{e}=\frac{\theta p_{e}}{2}$.

In this mixed strategy equilibrium, when the e-tailer randomizes between $\underline{p}_{e}$ and $\bar{p}_{e}$ with probabilities $\omega$ and $1-\omega$, respectively, the brick-mortar store's profit can be formulated as follows:

$$
\pi_{r}=\omega p_{r}\left(1-\frac{p_{r}-\frac{\theta p_{r}}{2}}{1-\theta}\right)+(1-\omega) p_{r} q_{r}
$$

The brick-mortar store sets its price to maximize its profit. The FOC yields the optimal price is: 
$p_{r}^{*}=\frac{(1-\theta)\left(\omega+(1-\omega) q_{r}\right)}{\omega(2-\theta)}$

i.e., $\sqrt{1-\theta}\left(1-q_{r}\right)=\frac{(1-\theta)\left(\omega+(1-\omega) q_{r}\right)}{\omega(2-\theta)}$

then:

$\omega=\frac{q_{r} \sqrt{1-\theta}}{(2-\theta-\sqrt{1-\theta})\left(1-q_{r}\right)}$

and:

$1-\omega=\frac{\left(1-q_{r}\right)(2-\theta)-\sqrt{1-\theta}}{(2-\theta-\sqrt{1-\theta})\left(1-q_{r}\right)}$

PROOF OF PROPOSITION 2: From Proposition 1, it is clear that the retailer's profit can be formulated as follows:

$\pi_{r}=\omega p_{r}\left(1-\frac{p_{r}-\frac{\theta p_{r}}{2}}{1-\theta}\right)+(1-\omega) p_{r} q_{r}$

By inserting:

$\omega=\frac{q_{r} \sqrt{1-\theta}}{(2-\theta-\sqrt{1-\theta})\left(1-q_{r}\right)}$

into the above expression:

$\pi_{r}=\frac{q_{r}\left(1-q_{r}\right)(2-\theta) \sqrt{1-\theta}}{2(2-\theta-\sqrt{1-\theta})}$

By FOC condition, $q_{r}^{*}=\frac{1}{2}$. Following that: 


$$
\begin{aligned}
& \pi_{r}=\frac{(2-\theta) \sqrt{1-\theta}}{8(2-\theta-\sqrt{1-\theta})} \\
& \pi_{d}=\frac{\theta}{16}
\end{aligned}
$$

PROOF OF PROPOSITION 3: Since $208 \theta^{2}-384 \theta+256>0$ for all $0<\theta<1$ :

$$
228 \theta^{2}+\theta^{4}-20 \theta^{3}-384 \theta+256>0
$$

and further:

$$
\frac{(2-\theta) \sqrt{1-\theta}}{8(2-\theta-\sqrt{1-\theta})}>\frac{4(1-\theta)}{(4-\theta)^{2}}
$$

(13) is always higher than (9), which shows that the profit achieved under commitment is always higher that achieved in non-commitment for the retailer.

PROOF OF LEMMA 3: By Karush-Kuhn-Tucker (KKT) conditions:

1. When $q_{o}^{r c} \geq \frac{1}{2}, p_{o}^{r c} \geq \frac{1}{2}$ and $p_{o}^{e c}=\frac{\theta}{2}$, therefore $\pi_{o}^{c}=\frac{1}{4}$;

When $q_{o}^{r c}<\frac{1}{2}, p_{o}^{r c}=\frac{2\left(1-q_{o}^{r c}\right)+\theta\left(2 q_{o}^{r c}-1\right)}{2}, p_{o}^{e c}=\frac{\theta}{2}$, therefore:

$\pi_{o}^{c}=\frac{4 q_{o}^{r c}(1-\theta)\left(1-q_{o}^{r c}\right)+\theta}{4}$

Compare 1 to 2 , the optimal results is 1), i.e., $p_{o}^{r c}=\frac{1}{2}$ and $p_{o}^{e c}=\frac{\theta}{2}$, and $\pi_{o}^{c}=\frac{1}{4}$.

Lemmas 4, 5 and 7 can be proved by KKT conditions in the same way as Lemma 3. 
Zhaoqiong Qin's research focus on supply chain management, operations management and logistics. Her research work has been published in Operations Research, International Journal of Logistics: Research and Application, International Journal of Mathematics Management, International of Applied Management Science and International Journal of Operational Research and Information Systems.

Wen-Chyuan Chiang is Professor of Operations Management at Collins College of Business Administration, The University of Tulsa. His research interests include revenue management, supply chain management, distribution and logistics, manufacturing operations, and Al applications to operations management problems. His research appears in Management Science, International Journal of Revenue Management, IIE Transactions, Decision Sciences, International Journal of Production Research, European Journal of Operational Research, Annals of Operations Research, Journal of the Operational Research Society and INFORMS Journal on Computing, among others.

Robert Russell is Professor of Operations Management at Collins College of Business Administration, University of Tulsa. His research interests focus on Integration and Optimization of Supply Chain Activities, Vehicle Routing, Metaheuristics for Combinatorial Optimization, Logistics and Sports Scheduling, Management Science and Revenue Management. 